Boise State University

ScholarWorks

$11-4-2016$

Modeling the Drivers of Land Use Change and Ecosystem Services Change in Three (3) Urban Sites of Idaho: Causal Approach Examining the Importance of Boundaries

Christopher Felt

Boise State University 


\section{Modeling the drivers of land use change and ecosystem services change in 3 urban sites of Idaho: Causal approach examining the importance of boundaries.}

Chris Felt, Boise State University

\section{Sites in Idaho}

- Southwest (Counties): Ada and Canyon

- North: Kootenai

- East: Bannock, Bingham, and Bonneville

\section{Research Questions}

- What administrative boundaries affect the landowner's decision to change the land use type of a parcel?

- What effect do the administrative boundaries have on this decision?

- Why do these administrative boundaries have these effects?

- Are the administrative boundaries and their effects on the land owner's decision making consistent across the three sites?

\section{Model}

- Optimal timing of development model (OTD)

- Economic Model

- Landowner's decision of land use change is the selection of the optimal land that maximizes her expected utility

- The optimal time for a parcel to be developed is when the following two conditions are met:

- The one time return from selling residential lots developed from the parcel, net of conversion costs, exceeds the present value of returns from the current (undeveloped) land use.

- The rate of increase in net returns is less than the interest rate (i.e. the present value of the net gains from postponing are less than zero.)



This image is of the zoning ordinance impact areas in Ada county (black lines). The red lines indicate parcels that are within a two kilometer of the boundary of the impact area. The parcel that are highlighted yellow are those change land use from 2001 to 2011.

\section{Abstract}

Ecosystem services are tied to land use change. However, it is not clea how administrative boundaries affect land use change which in turn change ecosystem services. Additionally, regression analysis does provide adequate support for causal inferences about the relation between land use change and administrative boundaries. In my research, I will use a multinomial logistic regression and the quasiexperimental method referred to as regression discontinuity design to understand the causal relations between land use change and several administrative boundaries in three sites in Idaho.
Causality and Regression Analysis

Regression analysis in social science is inadequate for causal inference

- Researchers "can never observe the outcome of both treatment and control on the same unit of observation at the same moment in time

Causal inference and spatial analysis

- Demonstrating causation is even more difficult for spatial analysis because many variables tend to be correlated over space.

\section{Methodology}

Multinomial Logistic Regression Discontinuity Design

Regression Discontinuity Design

Quasi-experimental

- Matching Observations

- Treatment Variable (Dummy)

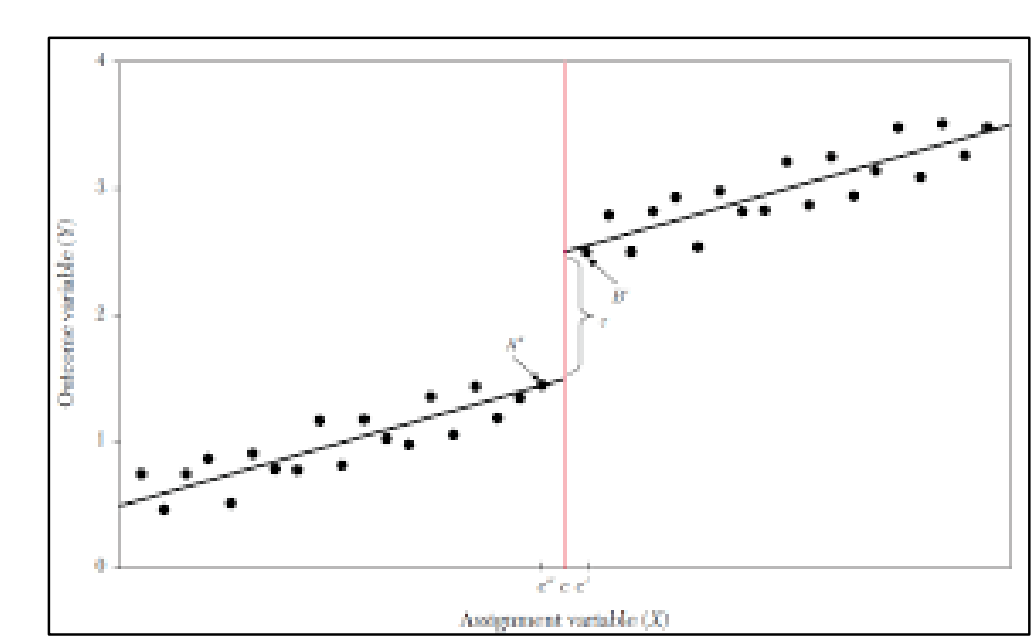

Variables

- Land use change from 2001 to 2011 (Parcels/Categorical)

- Administrative boundary variables (treatment)

- Parcel size

- Distance from city center

- Soil quality index

Data

- Parcel Data

- $\operatorname{NLCD}(2001,2006,2011)$

- Administrative Boundary Shapefiles

- Soil Shapefiles 